\title{
Research on the Integration of Urban and Rural Education Process study based on Analysis of Educational Financial Resources' Allocation
}

\author{
Dandan Wang \\ Southwest Jiaotong University,.Chengdu, Sichuan Province, China \\ $892529442 @ q q . c o m$
}

Keywords: Integration of education; Finance; allocation; Urban and rural

\begin{abstract}
This paper analyzes the education financial allocation of resources in promoting the process of the integration of urban and rural education, in order to understand the positive role of financial investment in education fairness and resource allocation. According to the current situation of the development of urban and rural education and the education finance in the distribution of different provinces, the author analyzes the cause for the differences between urban and rural areas, in order to provide reasonable suggestions.
\end{abstract}

\section{Introduction}

Education plays an important role in ChinaChina, along with economic development and income level, and thus residents need the high-quality \& diversified education. The broad masses of urban and rural residents hope to have good education environment, enjoy the high-qualified education resources, and satisfy their urgent pursuit of knowledge. Finance plays a fundamental role in realizing the integration of education, through the means of education funds and other education supervision of raising, distribution and use of resources. All in all, people realize the integration of urban and rural education is the key problem of modernization and democratization of education in China.

\section{The Role of Finance in the Integration of Urban and Rural Education}

First, the education finance ensures the material supplies for the development of education. Education acts as a kind of quasi-public goods, it has obvious externalities, and its social benefit is far greater than the interests of private sector. Government invests in education career through administrative means, including financial investment in education, teachers supply, building construction, education facilities, etc. This kind of investment is a long-term and huge project, it cannot achieve cost effective compensation and gain profits through the market mechanism, but it accelerates the progress of human society, promotes the growth of economy and the richness of country by externality.

Second, the education finance allocates the education resources efficiently. Rational allocation of education resources refers to the human, material and financial resources and the capital realize utility efficiently and allocate optimally. Resources are limited and human needs are infinite. To solve this contradiction between limited resources and infinite social needs reasonably, finance in the rational allocation of resources play an important role in the performance from two aspects: The first 
is effective allocation of resources among the different schools in the various areas. The second is reasonable allocation of resources in the infrastructure of education and the development of education career.

\section{The Reason of Urban and Rural Education Gap}

First the urban and rural dual economic structure. In the early days of China's foundation, China began to carry out the planned economic system, and formed the urban and rural dual economic structure, and China gave priority to developing heavy industry, promoted the urban development rapidly. In the rural areas, agriculture supports the industry, and the rural area supports the urban development. With the development of economy and the advance of reform and opening up, China carries out the strategy that allows some people to become prosperous first, and then make the other people rich, which further widen the income gap between urban and rural areas. The urban residents' income increases faster and its living standards improve rapidly. By contrast, due to the vulnerability of rural residents itself in the agricultural economy, the rural economic development has lagged for a long time. Moreover, the farmers' scientific and cultural quality is not high, making them feel difficult to enjoy the benefits from reform and opening up as the urban residents.

Second, Urban and rural dual economic structure led to the urban and rural dual education system directly. Obviously, the education resource allocation in China is preferential to the city, ignoring the countryside. Firstly, since the $1980 \mathrm{~s}$ China put forward to promoting the implementation of the nine-year compulsory education gradually. Although the compulsory education is both a right and an obligation, it is obvious that China gives priority to the development of urban compulsory education. The government lets the city school-age children receive nine-year compulsory education first, and then expands the coverage of rural areas. Secondly, the segmentation of education finance system enhances the dual education structure. Classification management system of local government's education finance system causes the rural education investment dislocation, and the educational gap between urban and rural areas has been widened. The burden of rural education fund passed on the villages and individual farmers. According to the additional tax provisions of the state education funds, urban residents shall be borne by the enterprises, while rural residents shall be borne by the individuals themselves. Combined with the policy, it substantially increases the burden of rural residents to receive compulsory education. Thirdly, the country puts more resources on the key schools, it virtually aggravates the imbalance of urban and rural education development, while ignores the countryside. Moreover, the rural teachers are flowing into cities, and the rural area faces the shortage of education resources and deterioration of educational condition. Lastly, many private education institutions are in pursuit of the cluster effectiveness of the education resources, choosing to invest the institutions in the city and not considering the rural areas. All in all, so many factors lead to the obvious gap between urban and rural education. It is difficult for the rural area to compete with the city, not only on the allocation of resources, but also on the development model.

\section{Policy and Recommendations}

First, break the urban and rural dual economic structure. Urban and rural dual economic structure is the key to restricting the urban and rural education. To break through the dual economic structure and change the policy of urban and rural, China begins to pay more attention to the process 
of urbanization, gradually realizes the importance of the integration of urban and rural areas, adjusts the structure of modern industry, takes the development of agriculture seriously, and narrows the gap between urban and rural areas. Besides, China put urban and rural areas into a unified system, develop together, and join hand in hand. With the economic development, urbanization has become an inevitable trend, urban and rural integration will eventually come true.

Second, break the structure of urban and rural education. In order to adapt to the development of the industrialization and the urbanization, education shall first focus on the rapid urban economic development, because the city has convenient transportation, the rapid development of the economic level, intensive business groups, strong financial supports, abundant education resources and teachers, and the convenient public infrastructure, which make the rural education development lag behind the city. At present, the income level of Chinese urban and rural residents is increased, the consumption structure is optimized, and they not only pursue the material civilization but the spiritual civilization. As a result, the development of rural education cannot satisfy the pursuit of better quality education for farmers. Therefor, it is a challenge to narrow the gap between urban and rural education to realize integration, which can promote China's modernization and urbanization.

Third, the rational allocation of financial resources. As one of the important contents of government public expenditure, according to the use of financial expenditure, education finance can be divided into education business and education infrastructure investment spending, the former accounts for $60 \%$ of spending on education. it is thus necessary to control the education spending, and make reasonable schedule among the regions, in order to make the urban and rural education financial allocate reasonably. Moreover, China must strive to give priority to meeting education business expending, and then put the remaining funds into infrastructure investment. It can ensure the rationality of education between urban and rural efficiently.

\section{References}

[1] Ishmael I. Munene,Wycliffe Otieno. Changing the Course: Equity Effects and Institutional Risk amid Policy Shift in Higher Education Financing in Kenya [J]. Higher Education, 2008, 554.

[2] Hua-shu Wang,Henk Moll. Education Financing of Rural Households in China [J]. Journal of Family and Economic Issues, 2010, 313.

[3] Raquel Fernández,Richard Rogerson. Education finance reform and investment in human capital: lessons from California [J]. Journal of Public Economics, 1999,743.

[4] Robert C. Knoeppel,Patricia F. First,Matthew R. Della Sala,Chinasa A. Ordu. Finance equity, student achievement, and justice: A five state analysis of equality of opportunity[J]. Journal of Educational Administration, 2014, 526.

[5] Andreas Follesdal. Equality of Education and Citizenship: Challenges of European Integration[J]. Studies in Philosophy and Education, 2008, 275.

[6] Yang Yang. Study of the Urban and Rural Education's Fairness in the Field of Public Service[J]. Chinese Studies, 2014, 0301.

[7] Chuanyou Bao. Policies for Compulsory Education Disparity between Urban and Rural Areas in China [J]. Frontiers of Education in China, 2006, 11. 
[8] Xin Shang,Rui Cui. The Necessity of Developing Rural Education under Chinese Urban and Rural Unitary Strategy [J]. Journal of Sustainable Development,2010,33.

[9] Baicai Sun,Jinyu Qi. Development of Ethnic Education and Educational Equality in China [J]. Frontiers of Education in China, 2007, 24.

[10] Andreas Follesdal. Equality of Education and Citizenship: Challenges of European Integration [J]. Studies in Philosophy and Education, 2008, 275. 